\title{
Low-dose docetaxel, estramustine and prednisolone combination chemotherapy for castration-resistant prostate cancer
}

\author{
MAYURA NAKANO $^{1}$, SUNAO SHOJI $^{1}$, TARO HIGURE ${ }^{1}$, MASAYOSHI KAWAKAMI $^{1}$, \\ TETSURO TOMONAGA ${ }^{1}$, TOSHIRO TERACHI ${ }^{2}$ and TOYOAKI UCHIDA ${ }^{1}$ \\ ${ }^{1}$ Department of Urology, Tokai University Hachioji Hospital, Hachioji, Tokyo 192-0032; \\ ${ }^{2}$ Department of Urology, Tokai University School of Medicine, Isehara, Kanagawa 259-1292, Japan
}

Received September 2, 2015; Accepted March 16, 2016

DOI: $10.3892 / \mathrm{mco} .2016 .830$

\begin{abstract}
The objective of this study was to report our experience with weekly low-dose docetaxel (DOC) chemotherapy for patients with castration-resistant prostate cancer (CRPC). From 2007 to 2014, 39 consecutive patients received weekly low-dose DOC; the oncological effectiveness, side effects and tolerability were prospectively analyzed. The median patient age, serum prostate-specific antigen (PSA) level and Gleason score at diagnosis of prostate cancer were 71 years (range, $55-83$ years), $187 \mathrm{ng} / \mathrm{ml}$ (range, $2.0-1711 \mathrm{ng} / \mathrm{ml}$ ) and 8 (range, 5-10), respectively. The median number of cycles of DOC was 7 (range, 1-45 cycles). Of the 39 patients, the PSA level decreased by $>50 \%$ in $13(33 \%)$. In the multivariate analysis of prediction of patient overall survival, a decrease of the PSA level to $<50 \%$ was a significant predictor (hazard ratio $=6.913 ; 95 \%$ confidence interval: $1.147-41.669 ; \mathrm{P}=0.035$ ). The median cancer-specific overall survival from the diagnosis of CRPC was 16.7 months (range, 2-54 months). Grade 3 toxicities were observed in 5 patients $(13 \%)$; specifically, limb edema, nausea and hepatic disorders were detected in $2(5 \%)$, $2(5 \%)$ and 1 patient $(3 \%)$, respectively. Treatment-related death (grade 5) occurred in 1 patient due to interstitial pneumonia after two courses of chemotherapy. The chemotherapy was completed in the majority of the patients $(n=37,94.8 \%)$ in the outpatient department, without interruption. These findings suggest that weekly low-dose DOC is feasible and safe for selected patients with CRPC, without treament with novel agents, such as abiraterone, enzalutamide and cabazitaxel.
\end{abstract}

Correspondence to: Dr Mayura Nakano, Department of Urology, Tokai University Hachioji Hospital, Hachioji, Tokyo 192-0032, Japan

E-mail: mayura1212@gmail.com

Key words: castration-resistant prostate cancer, docetaxel chemotherapy

\section{Introduction}

In the South West Oncology Group (SWOG9916) (n=770) and TAX $327(n=1,006)$ studies, the median overall survival $(\mathrm{OS})$ rate of patients treated with docetaxel (DOC)-based chemotherapy for castration-resistant prostate cancer (CRPC) was 2-3 months longer compared with the median OS of patients treated with mitoxantrone and prednisone (MP therapy). Specifically, in the SWOG9916 study, the OS with DOC-based chemotherapy was 17.5 months vs. 15.6 months with MP therapy $(\mathrm{P}=0.02)$; and in the TAX 327 study, the OS was 18.9 months with DOC every 3 weeks vs. 17.4 months with weekly DOC-based chemotherapy vs. 16.5 months with mitoxantrone $(\mathrm{P}=0.009)(1,2)$. Based on these reports, DOC-based chemotherapy was considered as the standard first-line treatment for patients with CRPC. Recently, molecular-targeted therapy for CRPC, including abiraterone (3) and enzalutamide (4), has been used for CRPC prior to DOC-based chemotherapy. However, some patients may have developed CRPC or show no response to new agents within a short period $(5,6)$. Thus, it may be meaningful to identify such patients and introduce DOC-based chemotherapy in the early phase of the disease.

Patients with CRPC may present with pain and anorexia, anxiety, constipation, diarrhea, sleep disturbances, mucositis, nausea, peripheral sensory neuropathy, rash, vomiting, urinary symptoms and fatigue $(7,8)$. DOC is associated with the risk of worsening the patients' physical status. Although standard-dose 3-weekly DOC (70-75 $\left.\mathrm{mg} / \mathrm{m}^{2}\right)$ has been widely used for CRPC, it has been associated with significant side effects. In previous studies, hematological toxicity (grade $\geq 3$ neutropenia) was found to be a major side effect of standard-dose 3-weekly DOC in $32-93 \%$ of the cases $(2,9)$. Therefore, patients treated with this regimen may have to withdraw from chemotherapy due to hematological toxicity. In the TAX 327 study, low-grade non-hematological toxicities occurred in at least $10 \%$ of the patients on standard-dose 3-weekly DOC, including fatigue, nausea and/or vomiting, alopecia and diarrhea. In the SWOG9916 study, non-hematological toxicities occurred in the patients treated with standard-dose 3-weekly DOC, compared with those treated with mitoxantrone, including cardiovascular events, nausea and vomiting, metabolic disturbances and neurological events. However, in previous studies, low-dose weekly DOC displayed comparable oncological effectiveness, 
with a lower rate of adverse events (AEs) compared with standard-dose 3-weekly DOC $(10,11)$. Therefore, low-dose weekly DOC may be of value for the treatment of patients with CRPC. The aim of the present study was to evaluate the usefulness of low-dose weekly DOC for CRPC patients in terms of oncological outcome, side effects and tolerability.

\section{Patients and methods}

Population. Patients who were treated with low-dose DOC between September, 2007 and April, 2014 were included in the present study. The eligibility criteria included histologically diagnosed adenocarcinoma of the prostate and confirmed failure of prior hormonal therapy. All the patients had an Eastern Cooperative Group performance status of $\leq 2$ prior to treatment.

Protocol of low-dose weekly DOC treatment. Treatment was repeated every 28 days on an outpatient basis. DOC $20 \mathrm{mg} / \mathrm{m}^{2}$ was administered on days 1, 8 and 15. Estramustine phosphate $280 \mathrm{mg}$ and prednisolone $5 \mathrm{mg}$ were taken orally every day.

DOC chemotherapy on day 1 was administered in the hospital for observation of AEs; after the second chemotherapy, it was administered during outpatient visits.

Analysis of oncological outcome. The primary endpoint was prostate-specific antigen (PSA) level decrease. The extent of decrease in the PSA levels of the patients who received DOC chemotherapy was evaluated in the present study. A PSA response was defined as a decrease from the pretreatment serum concentration by $50 \%$. PSA progression was defined as an increase in the serum PSA from the pretreatment level. To avoid early treatment discontinuation due to an increase in PSA level caused by tumor flare during the first weeks of DOC treatment, the first PSA assessment was performed 2 months after treatment initiation.

Analysis of AEs and tolerability. AEs were classified according to the Common Terminology Criteria for Adverse Events, version 4.0 (http://evs.nci.nih.gov/ftp1/ CTCAE/About.html). Treatment was discontinued due to disease progression or occurrence of severe AEs (grade $\geq 4$ ). Tolerability was evaluated using AEs and laboratory tests. The patients underwent a laboratory investigation, including a complete blood count and blood chemistry tests, including PSA, at least every 4 weeks.

Statistical analysis. All the statistical analyses were performed using IBM SPSS statistical software, version 19 (IBM SPSS, Armonk, NY, USA). The Kaplan-Meier product-limit method with log-rank comparisons was used to estimate survival distribution. The Cox's proportional hazards model was used to assess the prognostic significance of factors in the univariate and multivariate analyses. P-values of $<0.05$ were considered to indicate statistically significant differences.

\section{Results}

Patient characteristics. Between September, 2007 and April, 2014, 39 CRPC patients were treated with low-dose weekly DOC chemotherapy in our hospital. All the patients
Table I. Patient characteristics $(n=39)$.

\begin{tabular}{lc}
\hline Characteristics & Values, median (range) \\
\hline Age (years) & $71(55-83)$ \\
PSA at diagnosis (ng/ml) & $87(2.0-1,711)$ \\
Gleason score at diagnosis & $8(5-10)$ \\
DOC cycles (n) & $7(1-45)$ \\
Survival after DOC (months) & $16.7(1-45)$
\end{tabular}

PSA, prostate-specific antigen; DOC, docetaxel.

Table II. Adverse events of grade $\geq 3$ in the 39 CRPC patients treated with weekly low-dose docetaxel chemotherapy.

Adverse events ${ }^{\mathrm{a}}$

Patients, n (\%)

Hepatic enzyme increase

Interstitial pneumonia

Limb edema

Nausea

${ }^{\mathrm{a} C o m m o n}$ Terminology Criteria for Adverse Events, version 4.0. CRPC, castration-resistant prostate cancer.

had developed antiandrogen syndrome and received alternative antiandrogen therapy, and 29 patients (74\%) received ethinylestradiol. The patient characteristics are summarized in Table I. The median age at initiation of DOC was 71 years (range, 55-83 years) and the median serum PSA level at initial diagnosis was $187 \mathrm{ng} / \mathrm{ml}$ (range, 2.0-1,711 ng/ml). The median number of DOC cycles was 7 (range, $1-45$ cycles). The median Gleason score was unknown $(\mathrm{n}=4), 3+3(\mathrm{n}=3), 3+4(\mathrm{n}=6)$, $4+3(n=4), 4+4(n=5), 4+5(n=9), 5+4(n=5)$ or $5+5(n=3)$. The median PSA level at the initiation of DOC treatment was $50.1 \mathrm{ng} / \mathrm{ml}$ (range, $0.01-1,710 \mathrm{ng} / \mathrm{ml}$ ). There was no association between the PSA levels at initiation of DOC treatment and PSA response.

Of the 39 patients, $13(33 \%)$ responded to treatment with a decrease to $<50 \%$ of the PSA level. The median evaluation period of the PSA response was 3 months (range, 1-13 months). There was no response to chemotherapy in 9 patients $(27 \%)$.

AEs. The grade $\geq 3$ AEs are summarized in Table II. There was no significant hematological toxity. Grade 3 hepatic enzyme increase, limb edema and nausea were observed in $1(3 \%), 2(5 \%)$ and $2(5 \%)$ patients, respectively. One patient succumbed to interstitial pneumonia.

Survival analysis. The OS after treatment ranged from 2 to 54 months (median, 16.7 months) (Fig. 1). The results of the uni- and multivariate analysis of predictors of OS in the patient cohort are presented in Table III. In the univariate $(\mathrm{P}=0.019)$ as well as the multivariate analysis (hazard ratio $=6.913 ; 95 \%$ confidence interval: $1.147-41.669 ; \mathrm{P}=0.035$ ), the decrease of the PSA level to $<50 \%$ was a statistically significant factor predictive of survival. 
Table III. Univariate and multivariate analyses of predictors of overall survival in CRPC patients treated with low-dose DOC.

\begin{tabular}{|c|c|c|c|}
\hline \multirow[b]{2}{*}{ Variables } & \multirow{2}{*}{$\begin{array}{c}\begin{array}{c}\text { Univariate } \\
\text { analysis }\end{array} \\
\text { P-value }\end{array}$} & \multicolumn{2}{|c|}{ Multivariate analysis } \\
\hline & & P-value & $\begin{array}{c}\text { Hazard ratio } \\
(95 \% \text { confidence interval) }\end{array}$ \\
\hline Clinical stage (I/II vs. III/IV) & 0.9 & 0.7 & \\
\hline PSA level ( $\leq 20$ vs. > 20 ng/ml) & 0.8 & 0.7 & \\
\hline Gleason score (6/7 vs. $8-10)$ & 0.9 & 0.7 & \\
\hline Change in PSA level (<50 vs. $\geq 50 \%$ ) & 0.019 & 0.035 & $6.913(1.147-41.669)$ \\
\hline $\begin{array}{l}\text { PSA change within } 3 \text { months of DOC } \\
\text { therapy (increase vs. decrease) }\end{array}$ & 0.2 & 0.8 & \\
\hline $\begin{array}{l}\text { Time to initiation of DOC therapy } \\
\text { after PSA failure ( } \leq 12 \text { vs. }>12 \text { months) }\end{array}$ & 0.4 & 0.3 & \\
\hline
\end{tabular}

CRPC, castration-resistant prostate cancer; PSA, prostate-specific antigen; DOC, docetaxel.

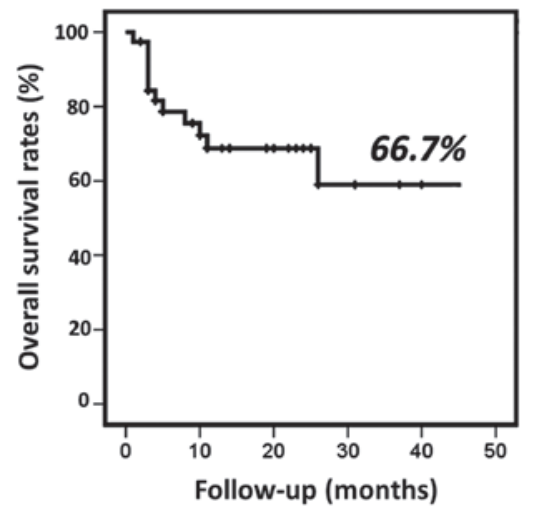

Figure 1. Overall survival rates of the patients after treatment.

\section{Discussion}

As of 2010, five new agents targeting CRPC, including abiraterone (3), enzalutamide (4), cabazitaxel, sipuleucel-T and radium-223, have been approved by the US Food and Drug Administration and the European Medicines Agency. These agents may be preferable to chemotherapy in patients with asymptomatic disease and in those with factors predisposing to poor torelance of chemotherapy. However, for patients with rapidly progressing disease or visceral metastases, or those with a poor response to initial androgen-deprivation therapy (ADT), the use of chemotherapy may be preferred. In the 2014 version of the European Association of Urology guidelines, DOC may be the treatment of choice for all patients with metastatic CRPC, excluding patients with with a performance status >2 (12). In the 2014 version of the American Society of Clinical Oncology guidelines, Basch et al suggested DOC and prednisone should be offered, but this type of therapy should be discussed with patients at the time of decision-making in relation to the apparently lower risk associated with other options and to the patient's individual circumstances (13). Pre-DOC therapy against CRPC with abiraterone acetate (14) and enzalutamide (15) demonstrated survival and quality-of-life benefits. DOC may exert its pharmacological effect without androgen receptor (AR). If patients with CRPC have developed early resistance to ADT, DOC should be used early during the course of treatment. Houédé et al (16) reported that patients with a high Gleason score (8-10) tended to respond poorly to abiraterone. Similarly, it was reported that patients with poorly differentiated cancers (Gleason score 8-10) benefit the most from DOC use (17). Therefore, DOC may be more suitable for patients with tumors of high Gleason score, particularly those with a durable response to initial ADT, who may benefit more from androgen-targeted therapies. In the present study, the percentage of patients with a Gleason score $>8$ was $63 \%$.

Since the approval of DOC in 2007, DOC-based chemotherapy has been widely administered to patients with CRPC. However, the patients were often forced to decrease the dose or suspend DOC due to AEs, particularly Asian patients (9). Kamiya et al (18) reported that the average body weight of Asian individuals is relatively low, resulting in a higher incidence of AEs. Only a limited number of studies have investigated the efficacy and tolerability of low-dose DOC in Asians (18-22). Nakai et al (20) reported that there was no significant difference in median time-to-progression between the standard-dose $\left(60-75 \mathrm{mg} / \mathrm{m}^{2}\right)$ and low-dose $\left(20-30 \mathrm{mg} / \mathrm{m}^{2}\right)$ groups (10.0 vs. $7.1 \mathrm{months}$, respectively; $\mathrm{P}=0.09$ ), whereas there were significantly fewer grade 3-4 hematological toxicities in the low-dose group compared with those in the standard-dose group ( 82.7 vs. $11.8 \%$, respectively). Shimabukuro et al (21) compared low(30-49 $\left.\mathrm{mg} / \mathrm{m}^{2}\right)$, medium- $\left(50-69 \mathrm{mg} / \mathrm{m}^{2}\right)$, and standard-dose $\left(\geq 70 \mathrm{mg} / \mathrm{m}^{2}\right)$ DOC and found no significant differences in survival among the DOC dose groups $(\mathrm{P}=0.3018)$; however, the incidence rate of grade 3 or 4 AEs associated with low-, medium- and standard-dose DOC treatment was 21.9, 35.7 and $90.7 \%$, respectively. Low-dose DOC may be a viable treatment option for CRPC patients who suffered from severe hematological AEs. In the TAX 327 study, the frequency of AEs was compared between 3-weekly and weekly DOC (1). Of note, the dose intensity of DOC for both regimens was the same, but there were significant differences in grade 3-4 neutropenia (32\% with 3 -weekly vs. $2 \%$ with weekly DOC). This result suggests that dividing the dosage of DOC into a weekly schedule may help reduce hematological events. 
As mentioned above, hematological AEs were more frequent in Asian CRPC patients treated with standard-dose DOC $(9,22-24)$. The incidences of grade 3-4 neutropenia and febrile neutropenia were significantly higher compared with those in the TAX 327 study (93.0\% with standard vs. 32\% with weekly; and $16.3 \%$ with standard vs. $3 \%$ with weekly, respectively) $(1,10)$. Furtheremore, several reports demonstrated that a dose reduction due to hematological toxity was required in 29.1-85.6\% of Asian CRPC patients (9,22-24), suggesting a higher incidence of severe hematological AEs in Asian populations treated with standard-dose DOC.

We observed no grade 3-4 hematological AEs in our cohort; however, 1 patient succumbed to interstitial pneumonia. The causative association between DOC and interstitial pneumonia has not been clearly explained. However, a sensitivity reaction to DOC is considered to be the cause, as the interstitial pneumonia often occurs after the second administration of DOC. Heidenreich et al reported symptomatic and extensive metastasis and rapid tolerance to first ADT as predictors of response to DOC in CRPC patients (12). Several poor prognostic factors have been described, such as visceral metastases, pain, anemia (hemoglobin concentration $<13 \mathrm{~g} / \mathrm{dl}$ ), bone scan progression, and estramustine administration prior to DOC. Patients were categorized into three risk groups and the median OS from the introduction of DOC to patient death was 25.7 months for the low-risk (0-1 factors), 18.7 months for the intermediate-risk (2 factors) and 12.8 months for the high-risk (3-4 factors) groups (25).

The PSA decline $\geq 50 \%$ in our study is comparable with previous studies $(1,2)$. The rate of PSA decline by $\geq 50 \%$ in our study was $41 \%$; the rate of PSA decline by $\geq 50 \%$ in the TAX 327 and SWOG9916 studies was 35 and 50\%, respectively $(1,2)$. In our study, there was no association between the PSA levels at the initiation of DOC treatment and PSA decline. However, the median duration of survival in our study was inferior (11.0 months in this study, 18.9 and 17.4 months with standard- and low-dose DOC, respectively, in TAX 327, and 17.5 months in SWOG9916) $(1,2)$. PSA values were dichotomized as $\leq 20$ or $>20 \mathrm{ng} / \mathrm{ml}$ in the univariate and multivariate analyses. PSA level was shown to be a potential predictor of CSS (26) and most prediction models define high-risk prostate carcinoma as a presenting PSA level of $>20 \mathrm{ng} / \mathrm{ml} \mathrm{(27),}$ with high risk defined as the risk of prostate cancer causing metastasis.

Our study has several limitations. First, this was a non-randomized retrospective study; therefore, conclusions should be interpreted with caution. Second, a sample size of 39 patients is not sufficiently large, thereby decreasing the stastical power of our results. Third, in the present study, $280 \mathrm{mg}$ of estramustine phosphate and $5 \mathrm{mg}$ of prednisolone were used daily. The differences in dose and duration of the administration of these drugs compared with those in the previous studies may affect the outcomes. Furthermore, the dosage of DOC differed between studies. Finally, we did not perform a comparison with patients treated with 3-weekly standard-dose DOC.

In conclusion, weekly low-dose DOC chemotherapy is a viable treatment option for patients with CRPC who are unable to tolerate the standard-dose regimen. Further studies are required to evaluate the usefulness of low-dose weekly DOC.

\section{References}

1. Tannock IF, de Wit R, Berry WR, Horti J, Pluzanska A, Chi KN Oudard S, Théodore C, James ND, Turesson I, et al: Docetaxel plus prednisone or mitoxantrone plus prednisone or mitoxantrone plus prednisone for advanced prostate cancer. N Engl J Med 351: 1502-1512, 2004.

2. Petrylak DP, Tangen CM, Hussain MH, Lara PN Jr, Jones JA, Taplin ME, Burch PA, Berry D, Moinpour C, Kohli M, et al: Docetaxel and estramustine compared with mitoxantrone and prednisone for advanced refractory prostate cancer. N Engl J Med 351: 1513-1520, 2004.

3. Fizazi K, Scher HI, Molina A, Logothetis CJ, Chi KN, Jones RJ, Staffurth JN, North S, Vogelzang NJ, Saad F, et al: Abiraterone acetate for treatment of metastic castration-resistant prostate cancer: Final overall survival analysis of the COU-AA-301 randomized, double-blind, placebo-controlled phase 3 study. Lancet Oncol 13: 983-992, 2012.

4. Scher HI, Fizazi K, Saad F, Taplin ME, Sternberg CN, Miller K, de Wit R, Mulders P, Chi KN, Shore ND, et al: Increased survival with enzalutamide in prostate cancer after chemotherapy. N Engl J Med 367: 1187-1197, 2012.

5. Harland S, Staffurth J, Molina A, Hao Y, Gagnon DD, Sternberg CN, Cella D, Fizazi K, Logothetis CJ, Kheoh T, et al: Effect of abiraterone acetate treatment on the quality of life of patients with metastatic castration-resistant prostate cancer after failure of docetaxel chemotherapy. Eur J Cancer 49: 3648-3657, 2013.

6. Francini E, Petrioli R and Roveiello G: No clear evidence of a sequential therapy regimen with abiraterone acetate and enzalutamide. Expert Rev Anticancer Ther 14: 1135-1140, 2014.

7. Scher HI, Morris MJ, Basch E and Heller G: End points and outcomes in castration-resistant prostate cancer: From clinical trials to clinical practice. J Clin Oncol 29: 3695-3704, 2011.

8. Sternberg CN, Molina A, North S, Mainwaring P, Fizazi K, Hao Y, Rothman M, Gagnon DD, Kheoh T, Haqq CM, et al: Effect of abiraterone acetate on fatigue in patients with metastatic castration-resistant prostate cancer after docetaxel chemotherapy. Ann Oncol 24: 1017-1025, 2013.

9. Naito S, Tsukamoto T, Koga H, Harabayashi T, Sumiyoshi Y, Hoshi $\mathrm{S}$ and Akaza H: Docetaxel plus prednisolone for the treatment of metastatic hormone-refractory prostate cancer: A multicenter phase II trial in Japan. Jpn J Clin Oncol 38: 365-372, 2008.

10. Horgan AM, Seruga B, Pond GR, Alibhai SM, Amir E, De Wit R, Eisenberger MA and Tannock IF: Tolerability and efficacy of docetaxel in older men with metastatic castrate-resistant prostate cancer (mCRPC) in the TAX 327 trial. J Geriatr Oncol 5: 119-126, 2014.

11. Italiano A, Ortholan C, Oudard S, Pouessel D, Gravis G, Beuzeboc P, Bompas E, Fléchon A, Joly F, Ferrero JM and Fizazi K: Docetaxel-based chemotherapy in elderly petients (age 75 and older) with castration-resistant prostate cancer. Eur Urol 55: 1368-1375, 2009.

12. Heidenreich A, Bastian PJ, Bellmunt J, Bolla M, Joniau S, van der Kwast T, Mason M, Matveev V, Wiegel T, Zattoni F, et al: EAU guidelines on prostate cancer. Part II: Treatment of advanced, relapsing, and castration-resistant prostate cancer. Eur Urol 65: 467-479, 2014.

13. Basch E, Loblaw DA, Oliver TK, Carducci M, Chen RC, Frame JN, Garrels K, Hotte S, Kattan MW, Raghavan D, et al: Systemic therapy in men with metastatic castration-resistant prostate cancer: American Society of Clinical Oncology and Cancer Care Ontario clinical practice guideline. J Clin Oncol 32: 3463-3448, 2014.

14. Rathkopf DE, Smith MR, de Bono JS, Logothetis CJ, Shore ND, de Souza P, Fizazi K, Mulders PF, Mainwaring P, Hainsworth JD, et al: Update interim efficacy analysis and long-term safety of abiraterone acetate in metastatic castration-resistant prostate cancer patients without prior chemotherapy (COU-AA-302). Eur Urol 66: 815-825, 2014

15. Beer TM, Armstrong AJ, Rathkopf DE, Loriot Y, Sternberg CN, Higano CS, Iversen P, Bhattacharya S, Carles J, Chowdhury S, et al; PREVAIL Investigators: Enzalutamide in metastatic prostate cancer before chemotherapy. N Engl J Med 371: 424-433, 2014.

16. Houédé N, Beuzeboc P, Gourgou S, Tosi D, Moise L, Gravis G, Delva R, Fléchon A, Latorzeff I, Ferrero JM, et al: Abiraterone acetate in patients with metastatic castration-resistant prostate cancer: Long term outcome of the Temporary Authorization for Use programme in France. BMC Cancer 15: 222, 2015. 
17. van Soest RJ, de Morrée ES, Shen L, Tannock IF, Eisenberger MA and de Wit R: Initial biopsy Gleason score as a predictive marker for survival benefit in patients with castration-resistant prostate cancer treated with docetaxel: Data from the TAX327 study. Eur Urol 66: 330-336, 2014.

18. Kamiya N, Suzuki H, Ueda T, Sato N, Nakatsu H, Mikami K, Sato N, Nomura K, Akakura K, Okano T, et al: Clinical outcomes by relative docetaxel dose and dose intensity as chemotherapy for Japanese patients with castration-resistant prostate cancer: A retrospective multi-institutional collaborative study. Int J Clin Oncol 19: 157-164, 2014.

19. Kita Y, Shimizu Y,Inoue T, Kamba T, Yoshimura K and Ogawa O: Reduced-dose docetaxel for castration-resistant prostate cancer has no inferior impact on overall survival in Japanese patients. Int J Clin Oncol 18: 718-723, 2013

20. Nakai Y, Nishimura K, Nakayama M, Uemura M, Takayama H, Nonomura N and Tsujimura A; Osaka CRPC Clinical Study Collaboration: Weekly, low-dose docetaxel combined with estramustine for Japanese castration-resistant prostate cancer: Its efficacy and safety profile compared with tri-weekly standard-dose treatment. Int J Clin Oncol 19: 165-172, 2014.

21. Shimabukuro T, Sakano S, Matsuda K, Kamiryo Y, Yamamoto N, Kaneda Y, Nasu T, Baba Y, Suga A, Yamamoto M, et al: Can docetaxel therapy improve overall survival from primary therapy compared with androgen-deprivation therapy alone in Japanese patients with castration-resistant prostate cancer? A multi-institutional cooperative study. Int J Clin Oncol 18: 62-67, 2013.
22. Miyake H, Sakai I, Terakawa T, Harada K and Fujisawa M Oncological outcome of docetaxel-based chemotherapy for Japanese men with metastatic castration-resistant prostate cancer. Urol Oncol 31: 733-738, 2011.

23. Nakagami Y, Ohori M, Sakamoto N, Koga S, Hamada R, Hatano T and Tachibana M: Safety and efficacy of docetaxel, estramustine phosphate and hydrocortisone in hormone-refractory prostate cancer patients. Int J Urol 17: 629-634, 2010.

24. Miura N, Numata K, Kusuhara Y, Shirato A, Hashine K and Sumiyoshi Y: Docetaxel-prednisolone combination therapy for Japanese patients with hormone-refractory prostate cancer: A single institution experience. Jpn J Clin Oncol 40: 1092-1098, 2010.

25. Armstrong AJ, Garrett-Mayer E, de Wit R, Tannock I and Eisenberger M: Prediction of survival following first-line chemotherapy in men with castration-resistant metastatic prostate cancer. Clin Cancer Res 16: 203-211, 2010.

26. D'Amico AV, Cote K, Loffredo M, Renshaw AA and Schultz D: Determinations of prostate cancer-specific survival after radiation therapy for patients with clinically localized prostate cancer. J Clin Oncol 20: 4567-4573, 2002.

27. Crawford ED, Bennett CL, Andriole GL, Garnick MB and Petrylak DP: The utility of prostate-specific antigen in the management of advanced prostate cancer. BJU Int 112: 548-560, 2013. 